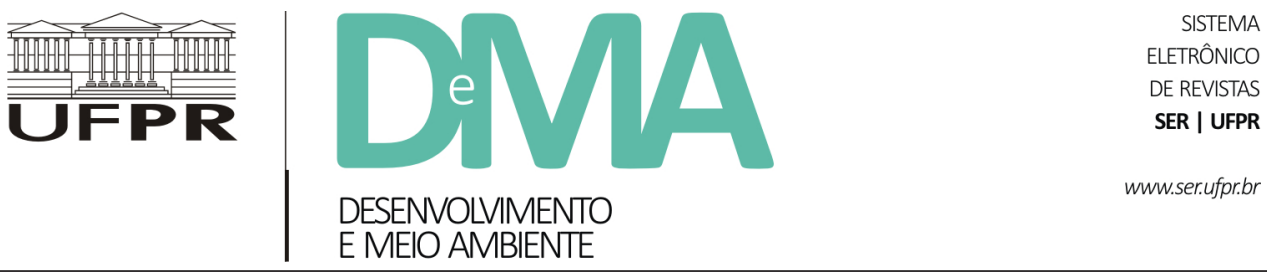

\title{
Aplicação de instrumento para avaliação de planos municipais de gestão integrada de resíduos sólidos ante às políticas públicas: estudo de caso do município de Rio Claro (SP)
}

\section{Application of an Assessment Tool for Municipal Waste Management \\ Plans Addressing Public Policies: Case Study in Rio Claro (São Paulo, Brazil)}

\author{
Ana Cristina Bagatini MAROTTI ${ }^{1 *}$, Cristine Diniz SANTIAGO ${ }^{1}$, Erica PUGLIESI ${ }^{1}$ \\ ${ }^{1}$ Programa de Pós-graduação em Ciências Ambientais (PPGCAm), Universidade Federal de São Carlos (UFSCar), São Carlos, SP. Brasil. \\ *E-mail de contato: ana_marotti@hotmail.com
}

Artigo recebido em 23 de março de 2016, versão final aceita em 19 de maio de 2017.

RESUMO: O Planejamento Municipal de Saneamento Básico é regulado, em nível nacional, pela Política Federal de Saneamento Básico, Lei n. 11.445/2007, e pela Política Nacional de Resíduos Sólidos, Lei n. 12.305/2010. Ambas trazem como instrumento os planos municipais de saneamento básico e de gestão integrada de resíduos sólidos, existindo a possibilidade de apresentação de ambos em um único documento. Nesse sentido, o presente trabalho buscou identificar a correlação existente entre a temática de resíduos nos planos municipais de saneamento básico e de gestão integrada de resíduos sólidos, e a forma de integração desses documentos, no que tange ao conteúdo mínimo legal, com base no estudo de caso em um município paulista. Para análise do plano municipal, considerando-se as políticas públicas mencionadas, foi desenvolvida uma matriz de análise que contempla os incisos I ao XIX do artigo 19 da Lei n. 12.305/2010 e a proposição de itens de verificação para a coleta de evidências objetivas, categorizando-os em requisitos atendidos, parcialmente atendidos ou não atendidos. Observou-se que o plano analisado não atende a esses conteúdos mínimos, o que prejudica o planejamento municipal no tocante aos resíduos sólidos, de maneira que se faz necessária a complementação dos planos elaborados. Por fim, considerou-se adequada a metodologia utilizada para esse tipo de análise, uma vez que pode ser facilmente replicada para situações similares e até mesmo utilizada para a comparação de diversos planos, além de ser um instrumento de fácil compreensão.

Palavras-chave: plano municipal de saneamento básico; resíduos sólidos; integração de políticas públicas; planejamento municipal.

ABSTRACT: The National Sanitation Policy, Law 11.445/2007, and the National Waste Policy, Law 12.305/2010, regulate municipal sanitation, and both present municipal plans as tools: sanitation and integrated waste management, 
with the possibility of joining both documents. Therefore, this paper aims to identify the correlation between both plans, as well as their integration, by analyzing the plan of a city in São Paulo's state, Brazil. In order to analyze this plan - regarding the policies previously mentioned -, we developed a comparison matrix, which contemplates subsections I to XIX from Law n. 12.305/2010 and proposes verification items to collect objective evidence and characterizes requirements as met, partially met or not met. The results provide evidence that the plan does not present the minimum content required and that it is harmful for municipal waste planning. Therefore, it is necessary to complement the plan. Also, the matrix developed for this analysis proved to be adequate for this kind of analysis, of easy comprehension. It is also easily replicable in similar situations, even for the comparison of several plans.

Keywords: sanitation municipal plan; solid waste; public policies integration; urban planning.

\section{Introdução}

Os serviços de saneamento básico são essenciais para a promoção da saúde pública, a conservação do meio ambiente, a manutenção em bom estado das estruturas urbanas, a limpeza pública e, de maneira mais ampla, a garantia da qualidade de vida da população (Heller \& Castro, 2013; Dodman et al., 2013). O saneamento básico entrou na pauta do governo brasileiro no início da década de 1930, em uma época de crescimento industrial e urbano no país. O Código de Águas (Decreto n. 24.643/1934) foi promulgado no governo Vargas e deu início à intervenção estatal nesse setor (Lucena, 2006). Nesse sentido, no ano de 2007 instituiu-se a Lei n. 11.445, que estabeleceu as diretrizes nacionais para o saneamento básico e a Política Federal de Saneamento Básico (Brasil, 2007).

A Política Federal de Saneamento Básico foi concebida de modo a abrigar todas as formas legalmente possíveis de organização institucional dos serviços de saneamento básico, buscando coerência com as múltiplas realidades sociais, ambientais e econômicas do Brasil (Pereira Jr., 2008), e tem como elemento principal a cooperação com municípios, estados e Distrito Federal na ampliação do acesso a serviços de saneamento básico de qualidade, contribuindo para a melhoria das condições de saúde e da qualidade de vida da população brasileira, com ênfase na redução das desigualdades regionais e sociais (Pereira Jr., 2008). São aspectos abordados pelo plano o conjunto de serviços de abastecimento público de água potável; a coleta, o tratamento e a disposição final adequada dos esgotos sanitários; a drenagem e o manejo das águas pluviais urbanas; a limpeza urbana e o manejo dos resíduos sólidos (Brasil, 2007). Segundo Pereira Jr. (2008), com a vigência dessa lei, era esperada uma ruptura no estado de imobilismo observado em boa parte dos municípios (os quais, apesar de deterem a titularidade dos serviços de saneamento básico e dos prestadores de serviço, têm deixado de investir na ampliação e na atualização desses serviços), tornando-se pioneira no estabelecimento de regras mínimas, de âmbito nacional, entre titulares, prestadores e usuários dos serviços no setor de saneamento básico.

Para o cumprimento dos objetivos da Política Nacional de Saneamento Básico, foram estabelecidos planos e programas, entre eles o Plano Nacional de Saneamento Básico (Plansab), de responsabilidade da União e sob a coordenação do Ministério das Cidades, e o Plano Municipal de Saneamento Básico (PMSB). O PMSB, a partir da Lei n. 11.445/2007, passou a ser uma exigência legal: para os municípios que não o apresentassem até 31 de dezembro de 2014, ficaria impedido o acesso aos recursos 
federais ou àqueles geridos ou administrados por órgão ou entidade da União, quando destinados a serviços de saneamento básico. Além disso, a partir de 31 de dezembro de 2015, a existência do PMSB constituiu condição sine qua non para o acesso a recursos orçamentários da União ou a recursos de financiamentos geridos ou administrados por órgão ou entidade da administração pública federal, quando destinados a serviços de saneamento básico, conforme o Decreto n. 8.211/2014 (Brasil, 2014).

O PMSB, após aprovado, torna-se instrumento estratégico de planejamento e gestão participativa. Ele deve ser elaborado por técnicos e encarregados da prefeitura, com a participação da sociedade e a aprovação em audiência pública, para posterior apreciação por parte dos vereadores e aprovação na Câmara Municipal (Sanepar, 2014).

Esse documento de planejamento do saneamento básico do município deve ser aprovado em consonância com os objetivos e as diretrizes dos planos plurianuais e com as legislações ambiental, de saúde e de educação. Além disso, o plano deve ser compatível com outras políticas públicas e objetos de planejamento municipal e regional, como os planos de bacia hidrográfica, os planos de resíduos sólidos e o Plano Diretor. Assim, o PMSB passa a ser a referência de desenvolvimento na temática, estabelecendo diretrizes e metas para o saneamento básico (Brasil, 2007; Funasa, 2010).

Apesar dos diversos e conhecidos benefícios advindos do saneamento básico, a realidade brasileira caracteriza-se por diversas deficiências e precariedade nesses serviços, marcados por grande desigualdade e déficit no acesso. Fragilidades como a indisponibilidade de água em quantidade e qualidade adequadas e a ineficiência (ou precariedade) dos serviços de esgotamento sanitário, limpeza pú- blica, manejo de resíduos sólidos e drenagem urbana se manifestam principalmente em escala municipal, afetando diretamente a população (Lisboa et al., 2013; Leoneti et al., 2011). A gestão dos resíduos sólidos tem destaque nesse cenário por representar um subproduto significativo do estilo de vida urbano, com taxa de crescimento mais elevada que a própria taxa de urbanização mundial, tendo em vista o incentivo ao consumo exacerbado e indiscriminado, inerente ao capitalismo (Hoornweg \& Bhada-Tata, 2012; Guerrero et al., 2013; Mesjasz-Lech, 2014).

No Brasil, a Política Nacional de Resíduos Sólidos (PNRS), instituída pela Lei n. 12.305/2010, uniformiza e disciplina, de maneira ampla, o tratamento da matéria dos resíduos sólidos, em oposição à abordagem generalizada da Política Federal de Saneamento Básico, e dá sequência ao conteúdo relativo a resíduos sólidos proposto anteriormente (Ribeiro, 2014; Failla, 2014). A PNRS traz como importantes instrumentos de gestão a elaboração de planos federal, estaduais e municipais de gestão integrada de resíduos sólidos, e apresenta diagnósticos, proposição de cenários, metas de gerenciamento e aproveitamento energético e eliminação de lixões. Dessa forma, ao incorporar esses elementos em função do aprimoramento dos conceitos envolvidos na gestão, apresenta-se um maior detalhamento do conteúdo do Plano Municipal de Gestão Integrada de Resíduos Sólidos (PMGIRS). A integração e a complementaridade evidente dessas políticas públicas possibilitam que o PMGIRS esteja inserido no PMSB, desde que respeitado o conteúdo mínimo previsto no artigo 19 da PNRS (Brasil, 2010).

Observa-se, portanto, a carga de responsabilidade imputada aos municípios, bem como a necessidade e a importância da elaboração dos planos municipais - tanto de saneamento básico quanto de 
gestão integrada de resíduos sólidos - como instrumentos de planejamento norteadores e legalmente obrigatórios. Destaca-se ainda a possibilidade de financiamento por parte da União para os municípios que apresentarem os planos, e, de maneira geral, para a melhoria da qualidade de vida urbana e o desenvolvimento municipal.

Com base no cenário legal apresentado e na realidade brasileira, o presente artigo se propõe a identificar a correlação existente entre os planos municipais de saneamento básico e de gestão integrada de resíduos sólidos, bem como de que forma se dá a integração desses documentos, no que tange ao conteúdo mínimo legal. Para tanto, propõem-se um instrumento para avaliação do conteúdo dos planos municipais de saneamento básico e a aplicação deste em um estudo de caso de um município paulista, buscando-se identificar o atendimento aos conteúdos mínimos da temática resíduos sólidos presentes na Lei n. 12.305/2010.

\section{Procedimentos metodológicos}

A fim de analisar a integração do PMGIRS com o PMSB, foram propostos um instrumento para avaliação do conteúdo dos planos, levando-se em consideração o atendimento aos conteúdos mínimos definidos no artigo 19 da Lei n. 12.305/2010, e a posterior aplicação desse instrumento em um estudo de caso de um município paulista.

\subsection{Concepção da matriz de análise}

$\mathrm{O}$ instrumento de avaliação, denominado Matriz de Análise, contemplou os incisos I ao XIX do artigo 19 da Lei n. 12.305/2010 e a proposição de itens de verificação (Figura 1).

Os itens de verificação visaram à coleta de evidências objetivas do cumprimento dos conteúdos dos incisos (requisitos), seja pela identificação da existência do elemento analisado ou pelo percentual de atendimento ao requisito analisado. $\mathrm{O}$ atendimento a um requisito ocorreu por meio de um ou mais itens de verificação, de acordo com a complexidade do requisito. Para a definição do percentual de atendimento de cada item de verificação, foram considerados os percentuais de 100, para o atendimento total do item, 50, para o atendimento parcial, e 0, para o não atendimento ao item.

Para a definição do atendimento do requisito, foram feitas a média dos itens de verificação correspondentes e a classificação destes em requisitos atendidos (que correspondem a 100\%), requisitos parcialmente atendidos (que apresentam porcentagem maior que $0 \%$ e menor que $100 \%$ ) e requisitos não atendidos (que correspondem a $0 \%$ ).

Para a análise do conteúdo do PMSB, foram propostos itens de verificação, para a identificação do conteúdo no plano, e considerações, para a apresentação de aspectos de relevância do conteúdo do plano.

\begin{tabular}{|c|c|c|c|c|c|}
\hline \multicolumn{3}{|c|}{ Lequisitos legais } & \multicolumn{3}{c|}{ Plano Municipal de Saneamento Básico } \\
\hline Incisos & Itens de verificação & $\begin{array}{c}\text { Valor } \\
(\%)\end{array}$ & $\begin{array}{c}\text { Atendimento } \\
(\%)\end{array}$ & Item & Considerações \\
\hline & & & & & \\
\hline
\end{tabular}

FIGURA 1 - Concepção da Matriz de Análise. 


\subsection{Aplicação da matriz de análise}

O estudo de caso é considerado um método adequado para abordar um fenômeno contemporâneo em pesquisas de planejamento municipal, explorando uma situação da vida real sem limites definidos de maneira clara e descrevendo a situação do contexto da investigação (Gil, 2002).

A escolha pela análise do plano do município de Rio Claro se deu em razão de seu PMSB ser recente (datado de fevereiro de 2014) e de sua proposta, a qual visa à abrangência do conteúdo mínimo do PMGIRS, constituindo um estudo ideal para a aplicação do instrumento.

\subsection{1. Área de estudo}

O município de Rio Claro está localizado na porção centro-leste do Estado de São Paulo (Figura 2), e conta com população de 186.253 habitantes e área de $498.422 \mathrm{~km}^{2}$ (IBGE, 2014). Faz parte da região administrativa de Campinas, importante polo
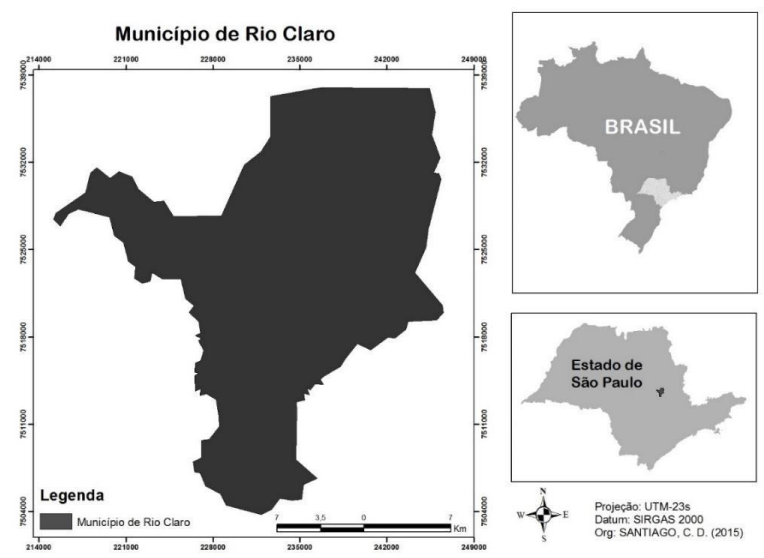

FIGURA 2 - Localização do município de Rio Claro. industrial, e é a segunda região que mais contribui para o crescimento do estado, após a região metropolitana de São Paulo. Sua localização estratégica em uma microrregião bastante desenvolvida e em constante expansão econômica influencia a economia municipal, de maneira que Rio Claro apresenta produção industrial diversa, destacando-se a produção de cerâmica, fibra de vidro, materiais plásticos, eletrodomésticos, entre outros produtos e materiais (Rossetti et al., 2007; Seade, 2015b).

No ano de 2014, o grau de urbanização do município era de 97,68\%, número superior à média estadual (96,21\%). Em sua quase totalidade, o município usufrui de serviços como coleta de resíduos sólidos, abastecimento de água e esgotamento sanitário (Seade, 2015a).

\section{Resultados e discussão}

\subsection{Abordagem da temática resíduos sólidos nos planos municipais}

A integração das políticas públicas se faz necessária em níveis nacional, regional e local. Ao se levar em consideração o conteúdo de um PMSB, é necessário que o planejamento esteja em consonância com o Plano Nacional de Saneamento Básico, o Plano de Bacia Hidrográfica, o Plano Diretor Municipal e os demais documentos correlatos que o município possua. Essa integração é essencial para a implementação bem-sucedida das políticas públicas (Oliveira \& Sampaio, 2012).

A respeito dos conteúdos do PMSB, do PMGIRS e de suas relações, Ribeiro (2012) considera que o primeiro refere-se exclusivamente aos ser- 
viços públicos de saneamento básico, enquanto o segundo tem objetivo distinto, uma vez que se destina a planejar a gestão ambientalmente adequada dos resíduos sólidos de diferentes tipologias gerados no município. Apesar de apresentarem enfoques diferenciados, é evidente que seus diagnósticos se assemelham, pois seus conteúdos estão interligados, considerando-se o PMGIRS como um aprofundamento de parte do PMSB. Além disso, seus resultados são ao mesmo tempo dependentes e complementares, razão pela qual a possibilidade de inserção do PMGIRS no PMSB é prevista pela Lei n. 12.305/2010, artigo 19, parágrafo $1^{\text {o: }}$.

O plano municipal de gestão integrada de resíduos sólidos pode estar inserido no plano de saneamento básico previsto no art. 19 da Lei no 11.445 , de 2007 , respeitado o conteúdo mínimo previsto nos incisos do caput e observado o disposto no $\S 2^{\circ}$, todos deste artigo. (Brasil, 2010)

Com base nessa proposição, é apresentada, a seguir, uma análise dos conteúdos mínimos dos planos municipais de gestão integrada de resíduos sólidos e de saneamento básico.

A Lei n. 11.445/2007 contém pouco detalhamento ou conteúdo norteador a respeito dos elementos a serem apresentados no PMSB, apresentando apenas em seu artigo 19 cinco incisos que tratam de sua abrangência mínima:

Art. 19. A prestação de serviços públicos de saneamento básico observará plano, que poderá ser específico para cada serviço, o qual abrangerá, no mínimo:

I - diagnóstico da situação e de seus impactos nas condições de vida, utilizando sistema de indicadores sanitários, epidemiológicos, ambientais e socioeconômicos e apontando as causas das deficiências detectadas;

II - objetivos e metas de curto, médio e longo prazos para a universalização, admitidas soluções graduais e progressivas, observando a compatibilidade com os demais planos setoriais;

III - programas, projetos e ações necessárias para atingir os objetivos e as metas, de modo compatível com os respectivos planos plurianuais e com outros planos governamentais correlatos, identificando possíveis fontes de financiamento;

IV - ações para emergências e contingências;

$\mathrm{V}$ - mecanismos e procedimentos para a avaliação sistemática da eficiência e eficácia das ações programadas. (Brasil, 2007)

Já a Lei n. 12.305/2010, também no artigo 19, aborda de maneira mais detalhada e específica o conteúdo mínimo necessário ao PMGIRS:

Art. 19. O plano municipal de gestão integrada de resíduos sólidos tem o seguinte conteúdo mínimo: I - diagnóstico da situação dos resíduos sólidos gerados no respectivo território, contendo a origem, o volume, a caracterização dos resíduos e as formas de destinação e disposição final adotadas;

II - identificação de áreas favoráveis para disposição final ambientalmente adequada de rejeitos, observado o plano diretor de que trata o $\S 1^{\circ}$ do art. 182 da Constituição Federal e o zoneamento ambiental, se houver; III - identificação das possibilidades de implantação de soluções consorciadas ou compartilhadas com outros Municípios, considerando, nos critérios de economia de escala, a proximidade dos locais estabelecidos e as formas de prevenção dos riscos ambientais; IV - identificação dos resíduos sólidos e dos geradores sujeitos a plano de gerenciamento específico nos termos do art. 20 ou a sistema de logística reversa na forma do art. 33, observadas as disposições desta Lei e de seu regulamento, bem como as normas estabelecidas pelos órgãos do Sisnama e do SNVS;

$\mathrm{V}$ - procedimentos operacionais e especificações mínimas a serem adotados nos serviços públicos 
de limpeza urbana e de manejo de resíduos sólidos, incluída a disposição final ambientalmente adequada dos rejeitos e observada a Lei ${ }^{\circ} 11.445$, de 2007;

VI - indicadores de desempenho operacional e ambiental dos serviços públicos de limpeza urbana e de manejo de resíduos sólidos;

VII - regras para o transporte e outras etapas do gerenciamento de resíduos sólidos de que trata o art. 20, observadas as normas estabelecidas pelos órgãos do Sisnama e do SNVS e demais disposições pertinentes da legislação federal e estadual;

VIII - definição das responsabilidades quanto à sua implementação e operacionalização, incluídas as etapas do plano de gerenciamento de resíduos sólidos a que se refere o art. 20 a cargo do poder público; IX - programas e ações de capacitação técnica voltados para sua implementação e operacionalização; $\mathrm{X}$ - programas e ações de educação ambiental que promovam a não geração, a redução, a reutilização e a reciclagem de resíduos sólidos;

XI - programas e ações para a participação dos grupos interessados, em especial das cooperativas ou outras formas de associação de catadores de materiais reutilizáveis e recicláveis formadas por pessoas físicas de baixa renda, se houver;

XII - mecanismos para a criação de fontes de negócios, emprego e renda, mediante a valorização dos resíduos sólidos;

XIII - sistema de cálculo dos custos da prestação dos serviços públicos de limpeza urbana e de manejo de resíduos sólidos, bem como a forma de cobrança desses serviços, observada a Lei $\mathrm{n}^{\circ} 11.445$, de 2007; XIV - metas de redução, reutilização, coleta seletiva e reciclagem, entre outras, com vistas a reduzir a quantidade de rejeitos encaminhados para disposição final ambientalmente adequada;

XV - descrição das formas e dos limites da participação do poder público local na coleta seletiva e na logística reversa, respeitado o disposto no art. 33, e de outras ações relativas à responsabilidade compartilhada pelo ciclo de vida dos produtos;

XVI - meios a serem utilizados para o controle e a fiscalização, no âmbito local, da implementação e operacionalização dos planos de gerenciamento de resíduos sólidos de que trata o art. 20 e dos sistemas de logística reversa previstos no art. 33;

XVII - ações preventivas e corretivas a serem praticadas, incluindo programa de monitoramento;

XVIII - identificação dos passivos ambientais relacionados aos resíduos sólidos, incluindo áreas contaminadas, e respectivas medidas saneadoras;

XIX - periodicidade de sua revisão, observado prioritariamente o período de vigência do plano plurianual municipal. (Brasil, 2010)

Nota-se, portanto, a diferença clara quanto ao detalhamento do conteúdo mínimo proposto para os planos municipais, o que pode interferir diretamente na elaboração desses planos, gerando dúvidas e incertezas. O conteúdo proposto para o PMGIRS é mais explícito e objetivo que o do PMSB, pois apresenta mais detalhamento das atividades e clareza de conteúdo. Ao estabelecer elementos de diagnóstico de diferentes tipologias de resíduos, identificação e monitoramento de passivos ambientais, proposição de metas, programas, indicadores de desempenho, cálculo de custos, monitoramento e periodicidade de revisão desses elementos, o PMGIRS institui instrumentos da gestão ambiental já em sua concepção. Por outro lado, o conteúdo proposto para o PMSB está mais relacionado a etapas de planejamento e revisão de atividades no âmbito dos serviços públicos municipais, o que o torna insuficiente para abarcar a complexidade dos resíduos gerados no território do município, e não contempla as diferentes responsabilidades e mecanismos de fiscalização no gerenciamento dos resíduos.

\subsection{O Plano Municipal de Saneamento Básico do município de Rio Claro}

A intervenção do Estado que se dá pelas políticas públicas pode ser compreendida como 
função intrínseca do Estado Moderno, na tentativa de garantir a manutenção e a perpetuação de uma parcela da população (Fleury, 1994 apud Moraes, 2009). Dessa forma, no que tange ao saneamento básico, faz-se necessária uma política pública que apresente as diretrizes para o setor, em termos de execução, operação, regulação, fiscalização e avaliação dos serviços. Ressalta-se que a participação social, além de ser obrigatória, é fator determinante no sucesso do planejamento municipal (Moraes, 2009; Marshall \& Farahbaksh, 2013).

A elaboração do PMSB do município de Rio Claro foi iniciada no mês de outubro de 2013 e finalizada em março de 2014, segundo as informações apresentadas no cronograma do plano. $\mathrm{O}$ plano foi elaborado em consonância com a Lei n. 11.445/2007, o Decreto Regulamentador n. 7.217/2010 e a Lei n. 12.305/2010 (especificamente em relação ao artigo 19, que apresenta o conteúdo mínimo do PMGIRS). Para a elaboração do PMSB, também foram consideradas as diretrizes estabelecidas por políticas correlatas, como o Estatuto das Cidades (Lei n. 10.257/2001), que define o acesso aos serviços de saneamento básico como um dos componentes do direito à cidade (Rio Claro, 2014).

$\mathrm{Na}$ elaboração do PMSB, foram definidos como objetivos

Atender todo o território (urbano e rural) do município de Rio Claro, e contemplar os quatro componentes do saneamento básico, que compreende o conjunto de serviços e infraestruturas e instalações operacionais de abastecimento de água, esgoto sanitário, drenagem e manejo de águas pluviais e limpeza urbana e manejo dos resíduos sólidos. (Rio Claro, 2014)
Para a elaboração do plano, a equipe responsável coordenou as atividades com base no termo de referência elaborado pela Fundação Nacional de Saúde - Funasa (2010). A primeira etapa contemplou a definição de um grupo de trabalho e foi seguida pela elaboração do diagnóstico e do prognóstico dos sistemas de abastecimento de água, esgotamento sanitário, drenagem pluvial e resíduos sólidos (Rio Claro, 2014).

A equipe de trabalho responsável pela elaboração do PMSB do município contou com a colaboração de uma empresa contratada para a operacionalização do processo de elaboração e com o auxílio de técnicos e representantes nomeados pela prefeitura municipal, os quais tinham a função de discutir e avaliar os trabalhos, criticar e sugerir alternativas, auxiliando na elaboração do plano e avaliando o andamento dos trabalhos do ponto de vista da viabilidade técnica.

O conteúdo do plano é embasado na estrutura apresentada no artigo 19 da Lei n. 11.445/2007 e inclui: a) plano de trabalho e plano de mobilização social; b) diagnóstico da prestação de serviços de saneamento básico; c) prognóstico e alternativas para universalização dos serviços de saneamento básico; d) objetivos e metas; e) relatório de concepção para os quatro eixos do serviço de saneamento básico; f) programas, projetos, ações e definições das ações de emergência e contingência; g) mecanismos e procedimentos de controle social para avaliação sistemática da eficiência e eficácia das ações programadas; $h$ ) versão preliminar do PMSB; e i) relatório do PMSB (Rio Claro, 2014). 


\subsection{Análise do Plano Municipal de}

Saneamento Básico e atendimento aos requisitos do Plano Municipal de Gestão Integrada de Resíduos Sólidos

Com base na aplicação do instrumento de análise proposto, apresenta-se a matriz de análise do conteúdo do PMSB de Rio Claro. Os itens de análise são oriundos do artigo 19 , parágrafo primeiro, da Lei n. 12.305/2010, que dispõe que "o plano municipal de gestão integrada de resíduos sólidos pode estar inserido no plano de saneamento básico previsto no artigo 19 da Lei n. 11.445, de 2007, respeitado o conteúdo mínimo previsto nos incisos do caput e observado o disposto no $\S 2^{\circ}$." (Brasil, 2010).

Os resultados são apresentados nas Tabelas 1 , 2 e 3 em função do percentual de atendimento aosrequisitos estabelecidos, os quais são classificados em requisitos atendidos, parcialmente atendidos e não atendidos.

Com base nos dados apresentados, observa-se que o PMSB de Rio Claro, apesar de ter a proposta de abranger também o PMGIRS, não o faz de maneira satisfatória em $63 \%$ de seu conteúdo, uma vez que três incisos não foram atendidos integralmente (16\%), nove foram contemplados parcialmente (47\%) e sete foram contemplados totalmente (37\%). Os incisos contemplados tratam de definições operacionais relativas ao transporte de resíduos, definição de responsabilidades, identificação de passivos, além da proposição de programas, que apresentam uma trajetória positiva do plano. No entanto, este acaba prejudicado pela ausência do conteúdo mínimo restante.
Aprofundando a análise do conteúdo não atendido pelo plano, pode-se considerar que o plano elaborado não incorporou instrumentos importantes para a gestão de resíduos sólidos previstos na Política Nacional, como a análise de alternativas de soluções consorciadas ou compartilhadas; as especificações mínimas e os procedimentos operacionais na gestão dos resíduos de responsabilidade dos serviços públicos; e os mecanismos de participação de grupos interessados, como associações e cooperativas de catadores.

É possível que a abordagem incompleta dos incisos no plano esteja relacionada às diferenças de objetivos e à abordagem das políticas, visto que, caso a equipe responsável pela elaboração não se atente a ambas, o resultado pode ser um plano geral, em oposição à demanda específica e técnica exigida pela PNRS, como considerado por Ribeiro (2014).

Temáticas essenciais, constantes também na Política Federal de Saneamento Básico, não foram satisfatoriamente atendidos, como o diagnóstico da situação atual sobre a gestão de resíduos sólidos e os mecanismos para o monitoramento da implantação do plano. $\mathrm{O}$ atendimento parcial por vezes ocorreu pela inexistência de informações de determinadas tipologias de resíduos, como estabelecimentos comerciais, serviços públicos de saneamento, agrossilvopastoris, transporte e mineração - atividades existentes no município. A ausência das informações referentes às etapas de gestão desses resíduos, assim como a ausência de informações acerca da apresentação dos planos de gerenciamento de resíduos por parte dos geradores e metas para redução, demonstra a fragilidade do plano e certo distanciamento do poder público municipal das responsabilidades a ele imputadas. 
TABELA 1 - Matriz de Análise do Plano Municipal de Saneamento Básico de Rio Claro (SP): requisitos atendidos.

Requisitos legais

Lei n. 12.305/2010 - art. 19
Plano Municipal de Saneamento Básico de Rio Claro

\begin{tabular}{cccc}
\hline Incisos & Itens de verificação & $\begin{array}{c}\text { Valor } \\
(\%)\end{array}$ & $\begin{array}{c}\text { Atendimento } \\
(\%)\end{array}$ \\
\hline
\end{tabular}

II - Identificação de áreas favoráveis para disposição final ambientalmente adequada de rejeitos, observado o plano diretor de que trata o $\S 1^{\circ}$ do art. $182 \mathrm{da}$ Constituição Federal e o zoneamento ambiental, se houver
Existência de identificação de áreas licenciadas para disposição final de rejeitos gerados no município (ex.: aterro sanitário, aterro industrial, aterro de resíduos de construção civil, quando aplicável)
As informações são apresentadas no item 3.4 (Diagnóstico do sistema de limpeza urbana e manejo de resíduos sólidos) e nos subitens 1.9.3 (Aterro sanitário de resíduos domiciliares) e 1.9 .4 (Aterro industrial)
Apresenta aterros licenciados como áreas de disposição final: aterro sanitário municipal, aterro industrial, aterro particular de resíduos de construção civil e aterro de resíduos de construção civil municipal em fase de licenciamento ambiental
VIII - Definiç̧ão das responsabilidades quanto à sua implementação e operacionalização, incluídas as etapas do plano de gerenciamento de resíduos sólidos a que se refere o art. 20 a cargo do poder público
Existência de identificação das responsabilidades a cargo do poder público na implantação

e na operacionalização do

\section{PMGIRS}

Existência de identificação das responsabilidades a cargo do poder público na implantação e na operacionalização dos demais planos de gerenciamento, quando aplicável
As informações são apresentadas em nos itens 3.4 (Diagnóstico do sistema de limpeza urbana e manejo de resíduos sólidos) e 1 (Infraestrutura de gerenciamento de resíduos sólidos)
O sistema de manejo de resíduos sólidos é de responsabilidade direta da Secretaria Municipal de Planejamento, Desenvolvimento e Meio Ambiente e de responsabilidade indireta, por meio do gerenciamento de contratos, de empresas para coleta, tratamento e destinação final. Já as atividades de varrição - limpeza pública - são de responsabilidade da Secretaria de Manutenção e Paisagismo. A respeito dos demais planos de gerenciamento (objeto do art. 20), nenhum é apontado pelo plano como de responsabilidade da gestão municipal 
X - Programas e ações de educação ambiental que promovam a não geração, a redução, a reutilização e a reciclagem de resíduos sólidos
Existência de programas e ações de educação ambiental que promovam a não geração, a redução, a reutilização e a reciclagem de resíduos sólidos
100
As informações são apresentadas nos itens 3.4 (Diagnóstico do sistema de limpeza urbana e manejo de resíduos sólidos) e 5.3 (Investimentos para o sistema de resíduos sólidos), e no subitem 1.9.5.2 (Projeto Coleta Seletiva nas Escolas)
O Projeto Coleta Seletiva nas Escolas, desenvolvido no município de Rio Claro, consiste em atividades de promoção da educação ambiental em escolas de níveis fundamental e médio
XII - Mecanismos para a criação de fontes de negócios, emprego e renda, mediante a valorização dos resíduos sólidos
Definição de mecanismos de fomento à criação de negócios e emprego e à geração de 100 100 renda
As informações são apresentadas no item 5.3 (Investimentos para o sistema de resíduos sólidos) e no subitem 5.3.4 (Implantar o Parque de Educação Ambiental-PEA)
No plano é proposta a criação, em parceria com a iniciativa privada, do Parque de Educação Ambiental (PEA) como centro de valorização dos resíduos sólidos e de inclusão social. É recomendado que essa estrutura seja implantada junto com $\mathrm{o}$ aterro de inertes, $\mathrm{o}$ qual está em fase de obtenção de licença

Definição de mecanismos de implantação de ações preventivas

Definição de mecanismos de implantação de ações corretivas

XVII - Ações preventivas e corretivas a serem praticadas, incluindo programa de monitoramento
Existência de programas de monitoramento das atividades do plano
As informações são apresentadas no item 4.4 (Prognóstico-infraestrutura de gerenciamento de resíduos sólidos) e no subitem 4.4.5 (Prever eventos de emergência e contingência), o qual contempla o plano de contingências e ações emergenciais
O subitem 4.4.5 visa à proposição de diretrizes e estratégias para ações e medidas de prevenção e controle de situações de risco e agravo, e à realização e regularidade dos serviços de limpeza urbana e manejo de resíduos sólidos do município. Nele também estão previstas medidas de monitoramento 
Identificação de passivos ambientais relacionados aos resíduos sólidos gerados no município

XVIII - Identificação dos passivos ambientais relacionados aos resíduos sólidos, incluindo áreas contaminadas, e respectivas medidas saneadoras
Identificação de áreas contaminadas no município

Proposição de medidas saneadoras para os passivos e as áreas contaminadas existentes 100 no município
As informações são apresentadas no item 3.4 (Diagnóstico do sistema de limpeza urbana e manejo de resíduos sólidos) e no subitem 1.9.5.6 (Área de passivo ambiental) em i. (Identificação e informação sobre áreas de risco de poluição/ contaminação e de áreas já contaminadas)
Existe ao lado do aterro sanitário do município uma área de passivo ambiental em virtude da disposição irregular de resíduos originários da limpeza de áreas clandestinas de descarte. Para tal área são apresentadas as medidas que serão tomadas. Também são identificadas e apresentadas as áreas contaminadas por resíduos sólidos no município
XIX - Periodicidade de sua revisão, observado prioritariamente o período de vigência do plano plurianual municipal
Definição da periodicidade de revisão do plano
As informações são apresentadas no item 6.6 (Acompanhamento do plano)
De acordo com a Lei Federal n. 11.445/2007, o PMSB deve ser revisto a cada quatro anos, sendo ouvida a população, reavaliadas as carências e revistos os objetivos e as metas, de maneira a transmitir ao plano a dinâmica das administrações municipais e a evolução positiva ou negativa dos serviços de saneamento básico prestados à população 
TABELA 2 - Matriz de Análise do Plano Municipal de Saneamento Básico de Rio Claro (SP): requisitos parcialmente atendidos.

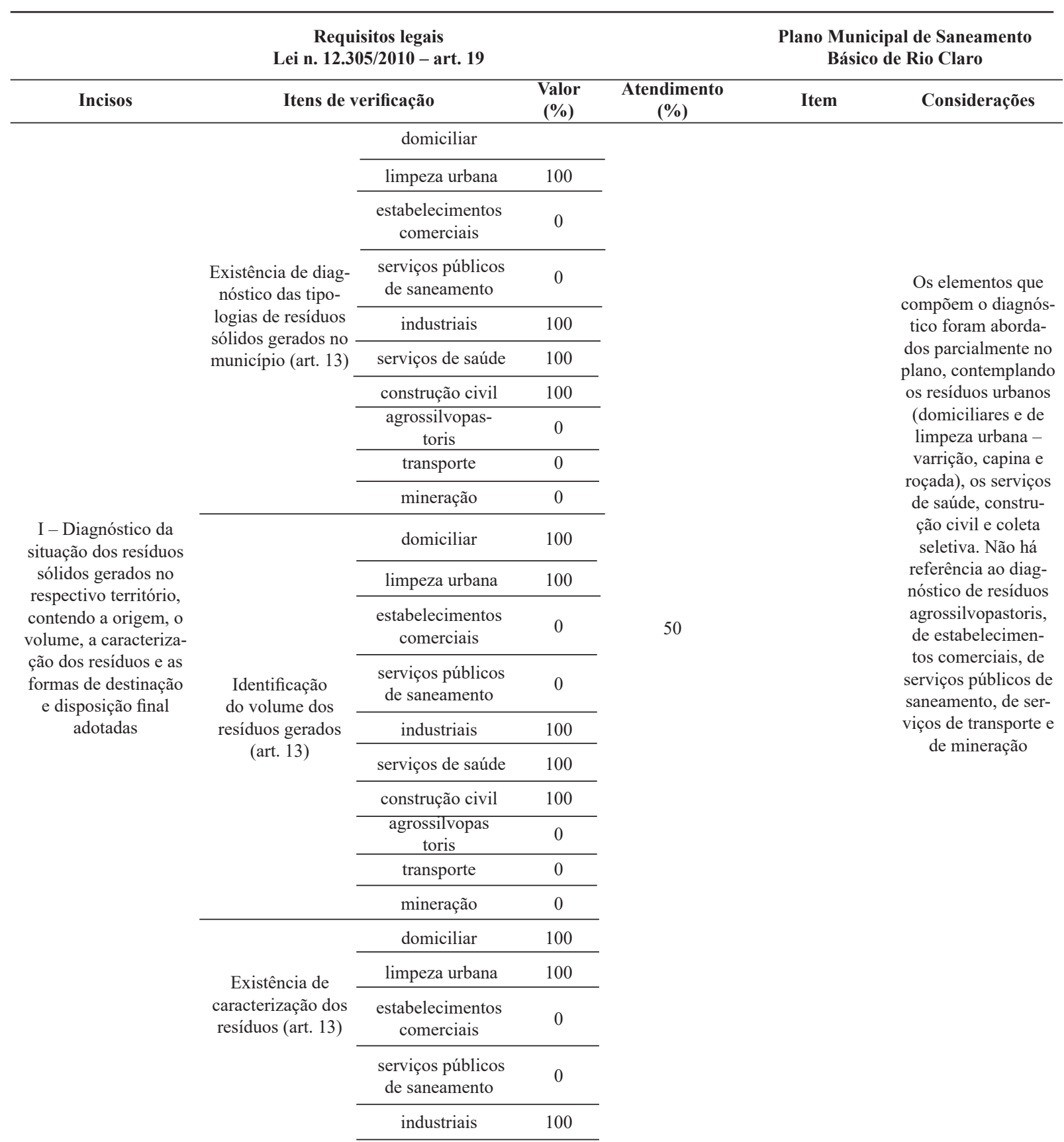




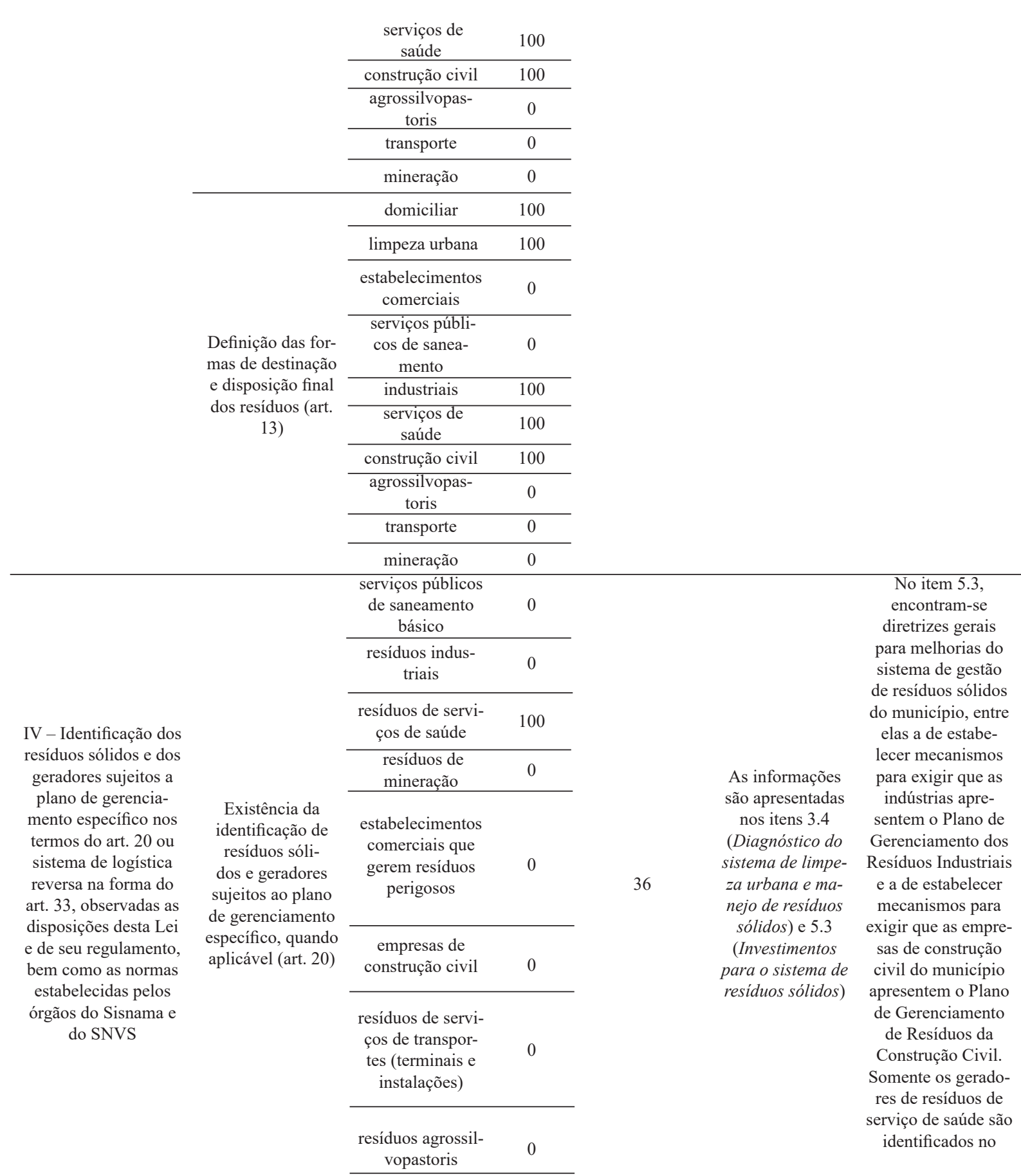




\begin{tabular}{cc} 
agrotóxicos & 0 \\
\hline pilhas e baterias & 100 \\
\hline pneus & 100 \\
\hline $\begin{array}{c}\text { óleos lubrifi- } \\
\text { cantes }\end{array}$ & 0 \\
\hline $\begin{array}{c}\text { lâmpadas } \\
\text { fluorescentes, de } \\
\text { vapor de sódio e } \\
\text { mercúrio e de luz } \\
\text { mista }\end{array}$ & 100 \\
\hline $\begin{array}{c}\text { produtos eletro- } \\
\text { eletrônicos e seus } \\
\text { componentes }\end{array}$ & 100
\end{tabular}

item 3.4 quanto à logística reversa.

Para algumas tipologias de resíduos, é apresentado o sistema adotado, porém para outras é citada ou abordada somente a forma de fiscalização, sem identificação da existência de um sistema de logística reversa

VI - Indicadores de desempenho operacional e ambiental dos serviços públicos de limpeza urbana e de manejo de resíduos sólidos

VII - Regras para o transporte e outras etapas do gerenciamento de resíduos sólidos de que trata o art. 20, observadas as normas estabelecidas pelos órgãos do Sisnama e do SNVS e demais disposições pertinentes da legislação federal e estadual

Existência de indicadores de desempenho operacional dos serviços de limpeza pública

100

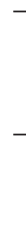

Existência de indicadores de desempe-
nho operacional do manejo de resíduos
sólidos

\begin{tabular}{cc}
\hline $\begin{array}{c}\text { Existência de indicadores ambientais } \\
\text { dos serviços de limpeza pública }\end{array}$ & 0 \\
\hline $\begin{array}{c}\text { Existência de indicadores ambientais } \\
\text { do manejo de resíduos sólidos }\end{array}$ & 0
\end{tabular}

\begin{tabular}{|c|c|c|c|}
\hline \multirow{7}{*}{$\begin{array}{l}\text { VII - Regras para o } \\
\text { transporte e outras eta- } \\
\text { pas do gerenciamento } \\
\text { de resíduos sólidos } \\
\text { de que trata o art. 20, } \\
\text { observadas as normas } \\
\text { estabelecidas pelos } \\
\text { órgãos do Sisnama e } \\
\text { do SNVS e demais } \\
\text { disposições pertinentes } \\
\text { da legislação federal e } \\
\text { estadual }\end{array}$} & \multirow{7}{*}{$\begin{array}{l}\text { Existência de } \\
\text { regramento para } \\
\text { o gerenciamento } \\
\text { e transporte dos } \\
\text { resíduos, quando } \\
\text { aplicável (art. 20) }\end{array}$} & $\begin{array}{c}\text { serviços públicos } \\
\text { de saneamento } \\
\text { básico }\end{array}$ & 0 \\
\hline & & $\begin{array}{l}\text { resíduos indus- } \\
\text { triais }\end{array}$ & 100 \\
\hline & & $\begin{array}{l}\text { resíduos de servi- } \\
\text { ços de saúde }\end{array}$ & 100 \\
\hline & & $\begin{array}{l}\text { resíduos de } \\
\text { mineração }\end{array}$ & 0 \\
\hline & & $\begin{array}{l}\text { estabelecimentos } \\
\text { comerciais que } \\
\text { gerem resíduos } \\
\text { perigosos }\end{array}$ & 0 \\
\hline & & $\begin{array}{c}\text { empresas de } \\
\text { construção civil }\end{array}$ & 100 \\
\hline & & $\begin{array}{l}\text { resíduos de servi- } \\
\text { ços de transpor- } \\
\text { tes (terminais e } \\
\text { instalações) }\end{array}$ & 0 \\
\hline
\end{tabular}

As informações são apresentadas no item 3.4

(Diagnóstico do sistema de limpeza urbana e manejo de resíduos sólidos)
Não são apresentados indicadores de desempenho ambiental. Os indicadores de desempenho operacional são apresentados com base nos indicadores do Sinis

As informações
a respeito do
funcionamento
do transporte
das diferentes
classes de resí-
duos sólidos são
apresentadas nos
itens
3.4 (Diagnóstico
do sistema de
limpeza urbana
e manejo de
resíduos sólidos),
que também in-
clui informações
gerais sobre o
gerenciamento, e
5.3 (Investimen-
tos para o siste-
ma de resíduos
sólidos)

No item 3.4, o plano apresenta um panorama geral da situação do gerenciamento dos resíduos no município, incluindo os serviços prestados e a infraestrutura disponível. É dada ênfase na disposição final, na qual são apresentados regramentos para a instalação e operação dos aterros 
resíduos agrossil-

vopastoris

IX - Programas e ações de capacitação técnica voltados para sua implementação e operacionalização
Existência de programas e ações de capacitação técnica voltados à implementação e à operacionalização 50 50
As informações são apresentadas nos itens 3.4

(Diagnóstico do sistema de limpeza urbana e manejo de resíduos sólidos) e 5.3

(Investimentos para o sistema de resíduos sólidos)
No item 5.3 , o texto do plano aponta a necessidade de capacitar os recursos humanos existentes na Central de Triagem de Recicláveis. Já no item 3.4, é informado que os catadores de resíduos sólidos recicláveis serão identificados, sensibilizados e capacitados para o desenvolvimento de ações do Programa Municipal de Economia Solidária. As ações voltadas à capacitação abordadas no plano são específicas para coleta seletiva, não havendo referência a outras ações de capacitação de recursos humanos envolvidos em outras atividades
Apresentação do sistema de cálculo dos custos da prestação dos serviços públicos de limpeza urbana

XIII - Sistema de cálculo dos custos da prestação dos serviços públicos de limpeza urbana e de manejo de resíduos sólidos, bem como a forma de cobrança desses serviços, observada a Lei n.

11.445, de 2007
Apresentação do sistema de cálculo dos custos da prestação dos serviços 0 públicos de manejo de resíduos sólidos

Apresentação da forma de cobrança 100 dos serviços de limpeza urbana

Apresentação da forma de cobrança dos serviços de manejo de resíduos sólidos
As informações são apresentadas nos itens 3.4 (Diagnóstico do sistema de limpeza urbana e manejo de resíduos sólidos) e 4.4 (Prognósticoinfraestrutura de gerenciamento de resíduos sólidos)
São informados os custos envolvidos, porém não é apresentado o sistema de cálculo dos custos para os serviços. Em relação à cobrança, o município não a realiza, porém enfatiza sua importância na sustentabilidade e manutenção dos serviços 
XIV - Metas de redução, reutilização, coleta seletiva e reciclagem, entre outras, com vistas a reduzir a quantidade de rejeitos encaminhados para disposição final ambientalmente adequada

\begin{tabular}{cc} 
domiciliar & 0 \\
\hline limpeza urbana & 0 \\
\hline $\begin{array}{c}\text { estabelecimentos } \\
\text { comerciais }\end{array}$ & 0 \\
\hline $\begin{array}{c}\text { serviços públi- } \\
\text { cos de sanea- } \\
\text { mento }\end{array}$ & 0 \\
\hline industriais & 0 \\
\hline $\begin{array}{c}\text { serviços de } \\
\text { saúde }\end{array}$ & 0 \\
\hline construção civil & 0 \\
\hline $\begin{array}{c}\text { agrossilvopas- } \\
\text { toris }\end{array}$ & 0 \\
\hline transporte & 0 \\
\hline mineração & 0
\end{tabular}

Existência de metas para reutilização de resíduos

0 geração das tipologias de resíduos no município

\begin{tabular}{cc}
\hline $\begin{array}{c}\text { construção civil } \\
\text { agrossilvopas- } \\
\text { toris }\end{array}$ & 0 \\
\hline transporte & 0 \\
\hline mineração & 0
\end{tabular}

Existência de metas para as atividades e o desempenho da coleta seletiva no município (ex.: ecopontos, recicláveis, 50 eletroeletrônicos, orgânicos, pneumáticos)

Existência de metas para atividades de reciclagem de resíduos 0

Existência de metas para outras ações que visam reduzir a geração de rejeitos
As informações são apresentadas nos itens 4.4

(PrognósticoInfraestrutura de gerenciamento de resíduos sólidos) e 5.3 (Investimentos para o sistema de residuos)
O inciso XIV foi abordado no plano pontualmente, indicando uma única meta: a de implantar

14 ecopontos nos próximos cinco anos na área urbana do município. O plano apresenta diretrizes para melhoria da gestão de resíduos sólidos no item 4.4 , porém não são definidas metas para contemplar os objetivos propostos. Com a proposição dos ecopontos, considera-se que estes podem envolver diversas tipologias de resíduos, porém sem definição de metas específicas para elas

Existência e forma de participação do poder público local nas atividades de coleta seletiva (ex.: local, transporte,

XV - Descrição das formas e dos limites da participação do poder público local na coleta seletiva e na logística reversa, respeitado o disposto no art. 33, e de outras ações relativas à responsabilidade compartilhada pelo ciclo de vida dos produtos programa, contratos, remuneração)

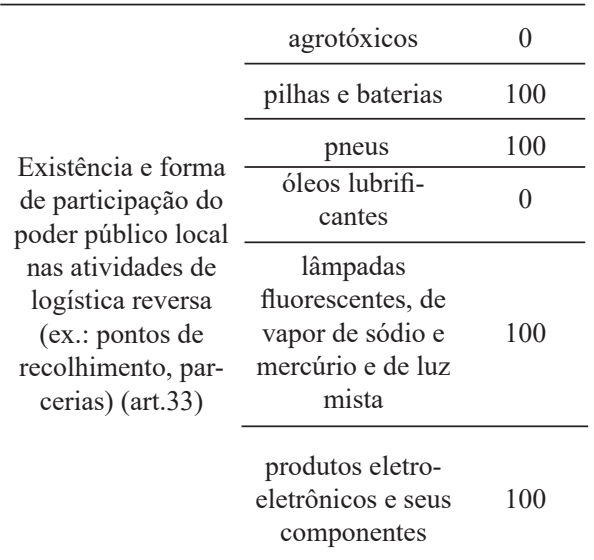

As informações são apresentadas nos itens 3.4 (Diagnóstico do sistema de limpeza urbana e manejo de resíduos sólidos) e 5.3

(Investimentos para o sistema de resíduos sólidos)
As formas de participação do poder público são apresentadas no diagnóstico.

Com relação à

logística reversa, as definições da participação do poder público são apresentadas somente para algumas tipologias de resíduos: pilhas e baterias, pneus, lâmpadas e produtos eletroeletrônicos 
XVI - Meios a serem utilizados para o controle e a fiscalização, no âmbito local, da implementação e operacionalização dos planos de gerenciamento de resíduos sólidos de que trata o art. 20 e dos sistemas de logística reversa previstos no art. 33

$$
+
$$

serviços público
de saneamento
básico

0

\begin{tabular}{ll}
\hline $\begin{array}{c}\text { resíduos indus- } \\
\text { triais }\end{array}$ & 0 \\
\hline $\begin{array}{c}\text { resíduos de servi- } \\
\text { ços de saúde }\end{array}$ & 0 \\
\hline $\begin{array}{l}\text { resíduos de } \\
\text { mineração }\end{array}$ & 0 \\
\hline
\end{tabular}

estabelecimentos

comerciais que

gerem resíduos

0

dos planos de

gerenciamento de

resíduos (art. 20)

perigosos

\begin{tabular}{cc}
\hline $\begin{array}{c}\text { empresas de } \\
\text { construção civil }\end{array}$ & 0 \\
\hline
\end{tabular}

resíduos de servi-

ços de transpor-

tes (terminais e

0 instalações)

resíduos agrossilvopastoris

0

\begin{tabular}{cc} 
agrotóxicos & 0 \\
\hline pilhas e baterias & 50 \\
\hline pneus & 50 \\
\hline $\begin{array}{c}\text { óleos lubrifi- } \\
\text { cantes }\end{array}$ & 50 \\
\hline
\end{tabular}

lâmpadas

fluorescentes, de

vapor de sódio e

mercúrio e de luz mista

produtos eletro-

eletrônicos e seus
As informações são apresentadas nos itens 5.3

(Investimentos para o sistema de resíduos sólidos e a respeito da logística reversa) e 3.4 (Diagnóstico do sistema de limpeza urbana e manejo de resíduos sólidos)
No item 5.3, encontram-se diretrizes gerais definidas para o serviço de resíduos sólidos do município, entre elas a de estabelecer mecanismo para exigir os planos de gerenciamento. No que se refere aos sistemas de logística reversa, são definidos os meios para operacionalização (pneus, pilhas e baterias, lâmpadas e produtos eletrônicos), porém sem definição dos meios de controle e fiscalização. A respeito dos óleos lubrificantes, define-se a responsabilidade de fiscalização sem definição da operacionalização

componentes 
TABELA 3 - Matriz de Análise do Plano Municipal de Saneamento Básico de Rio Claro (SP): requisitos não atendidos.

Requisitos legais

Lei n. 12.305/2010 - art. 19
Plano Municipal de Saneamento Básico de Rio Claro

\begin{tabular}{|c|c|c|c|c|c|}
\hline Incisos & Itens de verificação & $\begin{array}{c}\text { Valor } \\
(\%)\end{array}$ & $\begin{array}{c}\text { Atendimento } \\
(\%)\end{array}$ & Item & Considerações \\
\hline $\begin{array}{l}\text { III - Identificação } \\
\text { das possibilidades de } \\
\text { implantação de solu- } \\
\text { ções consorciadas ou } \\
\text { compartilhadas com } \\
\text { outros Municípios, } \\
\text { considerando, nos cri- } \\
\text { térios de economia de } \\
\text { escala, a proximidade } \\
\text { dos locais estabele- } \\
\text { cidos e as formas de } \\
\text { prevenção dos riscos } \\
\text { ambientais }\end{array}$ & $\begin{array}{l}\text { Existência de consórcios ou de análise de } \\
\text { possibilidades para implantação de solu- } \\
\text { ções consorciadas ou compartilhadas }\end{array}$ & 0 & 0 & $\begin{array}{l}\text { As informações são } \\
\text { apresentadas no } \\
\text { item } 3.4 \text { (Diagnós- } \\
\text { tico do sistema de } \\
\text { limpeza urbana e } \\
\text { manejo de residuos } \\
\text { sólidos) e na Tabela } \\
\text { 3.4.15 (Consórcios } \\
\text { intermunicipais } \\
\text { com gestão ou } \\
\text { serviços de manejo } \\
\text { de RSU) }\end{array}$ & $\begin{array}{c}\text { No item 3.4, } \\
\text { que contempla o } \\
\text { diagnóstico, não } \\
\text { são apresentadas } \\
\text { informações } \\
\text { sobre a análise } \\
\text { de possibilidades } \\
\text { de implantação } \\
\text { de soluções } \\
\text { consorciadas ou } \\
\text { compartilhadas } \\
\text { para qualquer } \\
\text { tipologia de } \\
\text { resíduos sólidos. } \\
\text { Na Tabela 3.4.15, } \\
\text { evidencia-se que } \\
\text { não há nenhum } \\
\text { tipo de consórcio } \\
\text { intermunicipal }\end{array}$ \\
\hline
\end{tabular}

V - Procedimentos operacionais e especificações mínimas a serem adotados nos serviços públicos de limpeza urbana e de manejo de resíduos sólidos, incluída a disposição final ambientalmente adequada dos rejeitos e observada a Lei $n$.

11.445, de 2007
Existência de procedimentos operacionais e especificações mínimas para serviços públicos de limpeza urbana

\begin{tabular}{c} 
varrição \\
\hline limpeza de \\
logradouros e vias \\
públicas - boca \\
de lobo
\end{tabular}

0

\begin{tabular}{ccc} 
& poda e capina & 0 \\
\hline & coleta & 0 \\
\cline { 2 - 3 } $\begin{array}{c}\text { Existência de } \\
\text { procedimentos ope- } \\
\text { racionais e especifi- } \\
\text { cações mínimas } \\
\text { para o manejo de } \\
\text { resíduos sólidos }\end{array}$ & transporte & 0 \\
\cline { 2 - 3 } & transbordo & 0 \\
\cline { 2 - 3 } & tratamento & 0 \\
\hline
\end{tabular}

Existência de procedimentos operacionais e especificações mínimas para disposição final de rejeitos
As informações são apresentadas no item 3.4 (Diagnóstico do sistema de limpeza urbana e manejo de resíduos sólidos)

$$
\begin{aligned}
& \text { As informações } \\
& \text { a respeito dos } \\
& \text { serviços de } \\
& \text { limpeza urbana } \\
& \text { são descritivas } \\
& \text { e superficiais, e } \\
& \text { não contemplam- } \\
& \text { procedimentos } \\
& \text { e especificações } \\
& \text { dos serviços } \\
& \text { realizados. Com } \\
& \text { relação ao ma- } \\
& \text { nejo de resíduos } \\
& \text { sólidos, apenas } \\
& \text { o diagnóstico é } \\
& \text { apresentado, sem } \\
& \text { contemplar os } \\
& \text { procedimentos } \\
& \text { operacionais ou } \\
& \text { especificações } \\
& \text { mínimas }
\end{aligned}
$$


Existência de programas que visem à participação de grupos interessados

XI - Programas e ações para a participação dos grupos interessados, em especial das cooperativas ou outras formas de associação de catadores de materiais reutilizáveis e recicláveis formadas por pessoas físicas de baixa renda, se houver (cooperativas, associação de catadores, ONGs, ou similares)

Existência de ações que visem à participação de grupos interessados (cooperativas, associação de catadores, ONGs, ou similares)
O plano não apresenta programa ou ação com esse caráter
As exigências do inciso XI não foram abordadas no plano
As atividades relacionadas à logística reversa e à coleta seletiva foram apresentadas de maneira incompleta, não compreendendo todas as tipologias de resíduos ou não definindo as responsabilidades e a participação do poder público na gestão. Tal fato denota as dificuldades ainda encontradas no país para a implantação tanto da logística reversa como da responsabilidade compartilhada pelo ciclo de vida dos produtos - instrumentos importantes de operacionalização da PNRS.

A ausência de metas de redução da geração de resíduos, bem como a não explicitação da necessidade de redução de material enviado indevidamente ou precocemente para a disposição final em aterro, aponta para deficiências estruturais importantes no conteúdo do plano, não observando a lógica de priorização definida na PNRS.

O conteúdo mínimo obrigatório do PMGIRS e a síntese dos dados analisados no PMSB são apresentados na Tabela 4.

Os dados apresentados indicam que não houve adequada integração do conteúdo do PMGIRS no PMSB, havendo necessidade de revisão para readequação do conteúdo mínimo previsto em lei. Apesar dessa constatação, ao se analisar as informações do Sistema Nacional de Informações sobre a Gestão de Resíduos Sólidos (Sinir) acerca da apresentação dos planos, consta que o município possui o PMGIRS.

TABELA 4 - Análise integrada do atendimento do Plano Municipal de Saneamento Básico do município de Rio Claro com o conteúdo mínimo para Plano Municipais de Gestão Integrada de Resíduos. 
II - Identificação de áreas favoráveis para disposição final ambientalmente adequada de rejeitos, observado o plano diretor de que trata o $\S 1^{\circ}$ do art. 182 da Constituição Federal e o zoneamento ambiental, se houver

Artigo atendido

III - Identificação das possibilidades de implantação de soluções consorciadas ou compartilhadas com outros Municípios, considerando, nos critérios de economia de escala, a proximidade dos locais estabelecidos e as formas de prevenção dos riscos ambientais

Artigo não atendido

IV - Identificação dos resíduos sólidos e dos geradores sujeitos a plano de gerenciamento específico nos termos do art. 20 ou sistema de logística reversa na forma do art. 33, observadas as disposições desta Lei e de seu regulamento, bem como as normas estabelecidas pelos órgãos do Sisnama e do SNVS
Artigo parcialmente atendido

V - Procedimentos operacionais e especificações mínimas a serem adotados nos serviços públicos de limpeza urbana e de manejo de resíduos sólidos, incluída a disposição final ambientalmente adequada dos rejeitos e observada a Lei ${ }^{\circ}$ 11.445, de 2007

Artigo não atendido

VI - Indicadores de desempenho operacional e ambiental dos serviços públicos de limpeza urbana e de manejo de resíduos sólidos

VII - Regras para o transporte e outras etapas do gerenciamento de resíduos sólidos de que trata o art. 20, observadas as normas estabelecidas pelos órgãos do Sisnama e do SNVS e demais disposições pertinentes da legislação federal e estadual
Artigo parcialmente atendido

Artigo parcialmente atendido

VIII - Definição das responsabilidades quanto à sua implementação e operacionalização, incluídas as etapas do plano de gerenciamento de resíduos sólidos a que se refere o art. 20 a cargo do poder público

IX - Programas e ações de capacitação técnica voltados para sua implementação e operacionalização

X - Programas e ações de educação ambiental que promovam a não geração, a redução, a reutilização e a reciclagem de resíduos sólidos

XI - Programas e ações para a participação dos grupos interessados, em especial das cooperativas ou outras formas de associação de catadores de materiais reutilizáveis e recicláveis formadas por pessoas físicas de baixa renda, se houver

XII - Mecanismos para a criação de fontes de negócios, emprego e renda, mediante a valorização dos resíduos sólidos

XIII - Sistema de cálculo dos custos da prestação dos serviços públicos de limpeza urbana e de manejo de resíduos sólidos, bem como a forma de cobrança desses serviços, observada a Lei n 11.445 , de 2007

XIV - Metas de redução, reutilização, coleta seletiva e reciclagem, entre outras, com vistas a reduzir a quantidade de rejeitos encaminhados para disposição final ambientalmente adequada

XV - Descrição das formas e dos limites da participação do poder público local na coleta seletiva e na logística reversa, respeitado o disposto no art. 33, e de outras ações relativas à responsabilidade compartilhada pelo ciclo de vida dos produtos

XVI - Meios a serem utilizados para o controle e a fiscalização, no âmbito local, da implementação e operacionalização dos planos de gerenciamento de resíduos sólidos de que trata o art. 20 e dos sistemas de logística reversa previstos no art. 33
Artigo atendido

Artigo parcialmente atendido

Artigo atendido

Artigo parcialmente atendido

Artigo atendido

Artigo não atendido

Artigo parcialmente atendido

Artigo parcialmente atendido

Artigo parcialmente atendido 


\section{Considerações finais}

Considera-se que a análise realizada no PMSB de Rio Claro não diverge de outros municípios do país, os quais, em grande parte, carecem de informações sistematizadas e corpo técnico especializado, o que os obriga a elaborar os planos de modo breve, preocupando-se mais com a apresentação do plano que com a qualidade de seu conteúdo. Essa postura não contribui de maneira efetiva para a melhoria dos deficientes serviços de saneamento básico no país.

Dessa forma, análises como a proposta neste artigo se apresentam como primeira etapa de um processo necessário de readequação dos planos municipais, a fim de avançar na gestão integrada de resíduos sólidos nos municípios.

Com base nos resultados alcançados, considera-se que o instrumento proposto se mostrou eficaz, pois permitiu a organização de dados e informações para a análise e síntese do plano analisado, podendo ser facilmente replicado. De modo complementar, a aplicação do instrumento em outros casos de estudo pode gerar um banco de dados nacional que permita análises mais aprofundadas das fragilidades e potencialidades de diversos planos, embasando possíveis ações no sentido de capacitação ou melhoria do planejamento.

Tendo em vista os resultados da análise do PMSB do estudo de caso, observa-se que este não está apto a substituir o PMGIRS, uma vez que não abrange o conteúdo mínimo destacado nos 19 incisos do artigo 19 da Lei n. 12.305/2010. Nesse sentido, é válido questionar se promulgar legislações nacionais de competências complementares realmente provocou a esperada ruptura no estado de imobilismo dos municípios, ou se o marco legal isolado não é suficiente para a ruptura desejada, sendo necessário um planejamento da implantação do disposto nas leis por meio de ações mais amplas e anteriores, como a capacitação técnica nos municípios e maior alinhamento de obrigações e conteúdos legais.

Apresenta-se, assim, uma importante discussão sobre a realidade dos planos de resíduos sólidos - inseridos ou não no PMSB -, uma vez que a fiscalização ou o controle desses planos estão geralmente relacionados à existência do plano, ficando desprovidos da análise técnica de conteúdo. Ao se considerar, por outro lado, o conteúdo mínimo a ser apresentado nos planos, podem ocorrer dúvidas e dificuldades de interpretação, além de ausência de dados e informações sistematizadas, tanto pela complexidade de exigências dos requisitos como pelas limitações encontradas nos municípios, que, de modo geral, apresentam demandas de recursos financeiros e capacitação adequada para desenvolver satisfatoriamente planos municipais de tamanha dimensão, como os de saneamento básico e resíduos sólidos. 
Dessa forma, faz-se necessário que as políticas públicas incorporem mecanismos de acompanhamento de conteúdo técnico dos planos apresentados pelos municípios - mesmo que se atenham ao atendimento do conteúdo mínimo -, compondo um documento consistente que permita a melhoria da gestão integrada de resíduos sólidos.

A qualidade dos planos se relaciona não apenas ao melhor planejamento no setor, mas também à promoção da saúde pública, à conservação do meio ambiente, à manutenção das estruturas urbanas, à limpeza pública e à consequente melhoria da qualidade de vida da população.

\section{Referências}

Brasil. Decreto n. 8.211, de 21 de março de 2014. Altera o Decreto n. 7.217, de 21 de junho de 2010, que regulamenta a Lei $\mathrm{n}^{\mathrm{0}} 11.445$, de 5 de janeiro de 2007, que estabelece diretrizes nacionais para o saneamento básico. Brasília: DOU de 24/3/2014.

Brasil. Lei n. 11.445, de 5 de janeiro de 2007. Estabelece diretrizes nacionais para o saneamento básico; altera as Leis nos 6.766, de 19 de dezembro de 1979, 8.036, de 11 de maio de 1990, 8.666, de 21 de junho de 1993, 8.987, de 13 de fevereiro de 1995; revoga a Lei no 6.528, de 11 de maio de 1978; e dá outras providências. Brasília: DOU de 8/1/2007 e retificado em 11/1/2007.

Brasil. Lei n. 12.305 de 02 de agosto de 2010. Institui a Política Nacional de Resíduos Sólidos; altera a Lei n. 9.605, de 12 de fevereiro de 1998; e dá outras providências, Brasília: DOU de 03/08/2010.

Dodman, D.; McGranahan, G.; Dalal-Clayton, B. Integrating the environment in urban planning and management: key principles and approaches for cities in the 21 st century. Nairobi: United Nations Environment Programme (UNEP), 2013.

Failla, V. Análise comparativa do Plano Nacional de Resí- duos Sólidos e do Plano Nacional de Saneamento Básico, quanto à gestão municipal dos resíduos sólidos. Monografia (Graduação em Engenharia Ambiental) - Escola de Engenharia de São Carlos da Universidade de São Paulo, 90p. 2014.

FUNASA - Fundação Nacional de Saúde. Termo de referência para elaboração de planos municipais de saneamento básico e procedimentos relativos ao convênio de cooperação técnica e financeira da fundação nacional de saúde. 2010. Disponível em: <http://www.funasa.gov.br/ site/wp-content/uploads/2011/10/TR_PMSB_2010.pdf>. Acesso em: mar. 2015.

Gil, A. C. Como elaborar projetos de pesquisa. São Paulo, v. 5, 2002.

Guerrero, L. A.; Maas, G.; Hogland, W. Solid waste management challenges for cities in developing countries. Waste management, 33(1), 220-232, 2013.

Heller, L.; Castro, J. E. Introdução. In: Heller, L.; Castro, J. E. (Org.). Política pública e gestão de serviços de saneamento. Editora UFMG, Belo Horizonte, 2013, 567p.

Hoornweg, D.; Bhada-Tata, P. What a waste: a global review of solid waste management. Washington DC: World Bank Group, 2012.98 p. (Urban Development Series Knowledge Papers).

IBGE. Instituto Brasileiro de Geografia e Estatística. $\mathrm{Ci}$ dades. Disponível em: https://goo.gl/CjGlAz. Acesso em: mai. 2014.

Leoneti, A. B.; Prado, E. L.; Oliveira, S. V. W. B. Saneamento Básico no Brasil: considerações sobre investimentos e sustentabilidade para o século XXI. Revista de administração pública, 45(2), 331-348, 2011.

Lisboa, S. S.; Heller, L.; Silveira, R. B. Desafios do planejamento municipal de saneamento básico em municípios de pequeno porte: a percepção dos gestores. Engenharia Sanitária e Ambiental, 18(4), 341-348, 2013.

Lucena, A. F. de. As políticas públicas de saneamento básico no Brasil: Reformas institucionais e investimentos governamentais. Revista Plurais, 1, 117-130, 2006.

Marshall, R. E.; Farahbakhsh, K. Systems approaches to integrated solid waste management in developing countries. 
Waste Management, 33(4), 988-1003, 2013.

Mesjasz-Lech, A. Municipal waste management in context of sustainable urban development. Procedia-Social and Behavioral Sciences, 151, 244-256, 2014.

Moraes, L. R. S. Política e Plano Municipal de Saneamento Básico: aportes conceituais e metodológicos. In: Cordeiro, B. S. (Coord.). Lei Nacional de Saneamento Básico, p. 31-52, 2009.

Oliveira, C. C.; Sampaio, R. S. R. (Org.). Instrumentos jurídicos para a implementação do Desenvolvimento Sustentável. Rio de Janeiro: FGV, Direito Rio, Programa em Direito e Meio Ambiente, 2012. 408 p.

Pereira JR, J. de S. Aplicabilidade da Lei 11.445/2007 Diretrizes nacionais para o saneamento básico. Estudo. Câmara dos Deputados, 2008. Disponível em: <https:// goo.gl/x0Ilqn $>$.

Rio Claro. Secretaria de Planejamento, Desenvolvimento e Meio Ambiente. Plano Municipal de Saneamento Básico do Município de Rio Claro. Fevereiro, 2014.

Ribeiro, W. A. A relação entre os marcos regulatórios do saneamento básico e dos resíduos sólidos. In: Jardim, A.; Yoshida, C.; Machado Filho, J. V. (Org.) Política Nacional, gestão e gerenciamento de resíduos sólidos. Barueri: Manole, 2012.
Ribeiro, W. A. A. Introdução à lei da Política Nacional de Resíduos Sólidos. In: Júnior, R. T.; Saiani, C. C. S.; Dourado, J. (Org.). Resíduos sólidos no Brasil: oportunidades e desafios da lei federal $n^{\circ} 12.305$ (lei de resíduos sólidos). Barueri: Minha Editora, 2014. p. 103-171.

Rossetti, L. A. F. G.; Pinto, S. A. F.; Almeida, C. M. Geotecnologias aplicadas à caracterização das alterações da cobertura vegetal intraurbana e da expansão urbana da cidade de Rio Claro (SP). In: Anais do XIII Simpósio Brasileiro de Sensoriamento Remoto, p. 5479-5486. INPE, 2007. Disponível em: <https://goo.gl/eOfl1E>.

SANEPAR - Companhia de Saneamento do Paraná. Plano Municipal de Saneamento Básico. Disponível em: $<$ https:// goo.gl/p2Cmj3>. Acesso em: jun. 2014.

SEADE - Fundação Sistema Estadual de Análise de Dados. Informações dos Municípios Paulistas - IMP. Disponível em: <https://goo.gl/RavnQs>. Acesso em: jul. 2015. [2015a].

SEADE - Fundação Sistema Estadual de Análise de Dados. SP Demográfico - Resenha de Estatísticas Vitais do Estado de São Paulo. Ano 15, n. 3, maio 2015. [2015b]. 